\title{
Does surgical release of neck burn contracture result in airway improvement?
}

\begin{abstract}
Objective: Burns of the neck are common injuries that may result in scar contractures, making intubation difficult. The widespread treatment of neck contractures for improvement of airway status is contracture release. We have reviewed our center's experience in release of neck contractures and subsequent airway status.

Methods: Retrospective chart review was conducted of all admissions with neck contractures at our center during the period spanning 1991-2011. In patients who underwent mentosternal contracture release, airway status during subsequent intubations was noted for improvement after release. Airway status assessed through comparison of Mallampati scores, thyromental distances, and Cormack and Lehane scores before and after contracture release.
\end{abstract}

Results: Of 734 charts reviewed, 9 patients fit our inclusion criteria, 3 had no improvement in airway status, 2 had exacerbation, and 4 had improvement.

Conclusion: Mentosternal contracture release does not necessarily translate into airway status improvement, possibly as contractures affect deep airway anatomy not treated by skin contracture release.

Keywords: contracture, neck, burns
Volume 7 Issue 6 - 2017

\author{
Shady N Hayek,' Arij M El Khatib,' Ghassan \\ Kanazi ${ }^{2}$ \\ 'Plastic and Reconstructive Surgery, Cosmetic Surgery Center, \\ Lebanon \\ ${ }^{2}$ Professor, Department and Anesthesiology, Lebanon
}

Correspondence: Arij M El Khatib, Plastic and Reconstructive Surgery, Cosmetic Surgery Center Beirut, Lebanon, Tel +961 3 989 I2I, Email arij@shadyhayek.com

Received: March 20, 2017| Published: April 13, 2017

\section{Introduction}

The face and neck are commonly involved in burn injuries in both adults and children. ${ }^{1}$ Scarring of these areas is frequent despite multiple treatment modalities, and often leads to important functional deficit as well as cosmetic concerns. Contractures of neck burns and the resulting difficulties in intubation due to inadequate neck extension, posterior displacement of the mandible, and microstomia have been frequently described in the literature. ${ }^{2}$ It is thought that by releasing the neck contractures and achieving an adequate soft tissue coverage, the intubation becomes easier. In this article we will review our experience with the change of intubation complexity after releasing neck burn contractures.

\section{Materials and methods}

Our study was conducted at the American University of Beirut Medical Center (AUBMC) in Beirut, Lebanon. Our Hospital is a Level I trauma and a tertiary care center. However, it does not contain a burn unit. After obtaining an institutional review board approval, we conducted a retrospective chart review of all burn cases admitted to our medical center from the years 1991-2011 in order to find any records of patients with mentosternal contractures due to burn injury who were difficult to intubate initially. Our inclusion criteria included all patients who were admitted with mentosternal/neck contractures secondary to burn injury who came later for another surgery and had their airway assessed properly and documented by an anesthesiologist. Our exclusion criteria included those patients who did not have any other surgery further to their scar release or those who had a subsequent surgery under local/ regional anesthesia. Comparisons were made in the airway classification between the original anesthesia assessment during the admission for the neck scar release and the assessment made at the subsequent surgery. The criteria measured were obtained from the anesthesia preoperative and intraoperative charts, Data was collected about the Mallampati and McCormack scores, as well as thyromental distance measurements that were used as indicators of anatomic distortions of the airway. In addition, remarks by anesthesiologists in their medical record about need for 'supplementary measures' to the regular intubation using a rigid Macintosh laryngoscope or fiberoptic intubation were noted.

\section{Results}

Out of a total of 734 patient charts reviewed for this study; 9 patients had limiting mentosternal contractures, underwent release of these contractures, and had presented for subsequent procedures necessitating intubation. Three of these 9 patients had no improvement, and 2 had decline in ease of intubation despite contracture release. Results are summarized in Table 1. The first patient with decline in ease of intubation was a male child that had sustained 15\% TBSA burn due to a scald with hot water at 1 year of age. He was initially treated in an outside hospital and presented to our center 1 month after the burn injury with $3^{\text {rd }}$ degree neck burns necessitating excision and grafting. Patient was noted to have limited neck extension despite a McCormack and Lehane score of 1 prior to burn excision and grafting. One month after excision and grafting, the patient was readmitted for excision of back burns and was found to have a worsening Cormack score of 2. No Mallampati score or thyromental distance recordings were found in the chart of this patient.

The second patient with worsening airway status was a 4 year old boy involved in a tent fire at the age of 4 years that resulted in deep burns to $20 \%$ TBSA. He presented to our center 1 year after the initial incident with severe thyromental contracture, Cormack and Lehane score of 3 and required fiberoptic laryngoscopy for intubation. One month after contracture release and split-thickness skin grafting, he underwent release of hand contracture and was observed to still have difficult airway and a McCormack and Lehane score of 4. No 
Mallampati score or thyromental distance recordings were found in the chart of this patient. The third patient is a 36 -year-old woman who was sustained a scald at the age of 14 years resulting in a Mallampati score of 2 and very limited neck extension when undergoing contracture release and split-thickness skin grafting. This patient showed the same Mallampati score and airway status at her subsequent surgery 6 months after her contracture release and grafting. The fourth patient was a 23 -year-old woman who was a blast injury victim at the age of 17 years and presented with a Mallampati score of 3 and thyromental distance of 3 fingers, had neck contracture band that was released with multiple z-plasties. Her airway assessment had the same indicators 4 years later when she presented for an appendectomy.

Table I Summary for the patients included in the review

\begin{tabular}{|c|c|c|c|c|c|c|}
\hline Patient & Gender & Age at burn & $\begin{array}{l}\text { Age at contracture } \\
\text { release }\end{array}$ & Type of intervention & $\begin{array}{l}\text { Age at subsequent } \\
\text { surgery }\end{array}$ & Ease of intubation \\
\hline I & $M$ & 13 months & 14 months & STSG & 15 months & $\begin{array}{l}\text { Worsened (Worsening Cormack } \\
\text { and Lehane score Iè2) }\end{array}$ \\
\hline 2 & $M$ & 4 years & 5 years & STSG & 5 years & $\begin{array}{l}\text { Worsened (Worsening Cormack } \\
\text { and Lehane score 3è4) }\end{array}$ \\
\hline 3 & $\mathrm{~F}$ & 14 years & 36 years & STSG & 37 years & No change (Mallampati score 2) \\
\hline 4 & $\mathrm{~F}$ & 17 years & 23 years & $\begin{array}{l}\text { Contracture Band release } \\
\text { and z-plasties }\end{array}$ & 27 years & $\begin{array}{l}\text { No change (Mallampati score } 3 \text {, } \\
\text { thyromental distance } 3 \text { fingers) }\end{array}$ \\
\hline 5 & $\mathrm{~F}$ & 51 years & 52 years & STSG & 52 years & $\begin{array}{l}\text { No change (Cormack and Lehane } \\
\text { score } 3 \text { ) }\end{array}$ \\
\hline 6 & $M$ & II years & 12 years & STSG & 13 years & $\begin{array}{l}\text { Improved (Cormack and Lehane } \\
\text { 3è2) }\end{array}$ \\
\hline 7 & $M$ & 12 years & 13 years & STSG & 13 years & $\begin{array}{l}\text { Improved (Cormack and Lehane } \\
\text { 3è2) }\end{array}$ \\
\hline 8 & $\mathrm{~F}$ & 50 years & 51 years & STSG & 56 years & Improved (Mallampati score 2èl) \\
\hline 9 & $M$ & 7 years & 10 years & STSG & 10 years & $\begin{array}{l}\text { Improved (Cormack and Lehane } \\
\text { 2èl) }\end{array}$ \\
\hline
\end{tabular}

Patient number 5 is a 52-year-old woman who sustained an oil burn to face and neck 1 year prior to admission, and was found to have a mentosternal contracture with limited neck extension and a Cormack and Lehane score of 3. She underwent contracture release and skin grafting, and had similar airway findings in subsequent surgery 3 months later. Patient required fiberoptic laryngoscopy for intubation during both procedures. The four patients with improving intubation parameters after contracture release are: patient number 6, a 12-year-old boy who presented one year after sustaining a blast injury resulting in a neck contracture with a Cormack and Lehane score of 3 . He underwent split-thickness skin grafting and returned a year later for further release of axillary contractures with an improved Cormack and Lehane score of 2. Patient number 7 is a 13 -year-old boy who presented with a Cormack and Lehane score of 3 one year after sustaining flame burns to most of his upper body as a result of a barbeque accident where alcohol was sprayed on open flame. Patient's neck contracture was released and split thickness skin grafting was performed. He was found to have a Cormack and Lehane score of 2 eight months later when he presented for further scar revisions. The eighth patient is a 50 -year-old woman presenting with a neck contracture and Mallampati score of 2 several months after a cooking accident resulted in her being burned with hot oil on $10 \%$ of her total body surface. Split-thickness skin grafting was performed and patient was lost to follow-up until 5 years later when she presented for a laparoscopic cholecystectomy and was documented to have a Mallampati score of 1 by the anesthesiologist. The ninth patient is a 10 -year-old boy who was burned by open flames at the age of 7 years, patient was documented to have a Cormack and Lehane score of 2 at first presentation to our hospital, this improved to a score of 1 six months after release of contracture and split-thickness skin grafting.

\section{Discussion}

Patients with neck contractures are notorious for the difficulty of their intubation, and the inability to intubate them may result in significant morbidity and possible mortality.,3 Degree of intubation difficulty is assessed by anesthesiology specialists using a number of physical signs and scores as well as radiologic imaging. The most notable and frequently used clinical signs are the extent of neck mobility, the Mallampati score, the McCormack and Lehane score, and the thyromental distance. The Mallampati score is a numerical score ranging from 1 to 4 given to a patient based on visualization of intraoral anatomical landmarks when a patient opens his/her mouth; with a score of 1 signifying visualization of fauces, pillars, soft palate, and uvula; score of 2 given upon visualization of fauces, soft palate, and uvula; score of 3 given upon visualization of soft palate and base of uvula; and a score of 4 signifying visualization of only the hard palate. ${ }^{4,5}$ The Cormack and Lehane Classification system grades visualization of an airway during direct laryngoscopy into 4 grades, with grade 1 providing a full view of the glottis including the airway, grade 2 giving a patial glottis view, grade 3 affording a view only of the epiglottis, and grade 4 furnishing only a view of the soft palate without epiglottis visualization. ${ }^{4,5}$

The thyromental distance is the distance between the tip of the mentum and the thyroid notch, measured with the head in full extension. A distance of less than $6-7 \mathrm{~cm}$, or roughly 3 adult finger breadths, has been reported to correlate with intubation difficulty. ${ }^{6}$ The clinical airway assessment tools mentioned above may be subject to inter-observer variability. ${ }^{7}$ Multiple studies have attempted to quantify the sensitivity and specificity values of the different clinical predictors of difficult intubation, and these values vary widely in the literature..$^{8-10}$ Many authors are in agreement that one value alone has low positive predictive value for difficult airway/intubation and therefore advocate the use of ${ }^{2}$ or more tests in conjunction to give a more significant assessment of airway difficulty. ${ }^{8-11}$ Further complicating airway assessment and intubation is the patients' compliance during induction of anesthesia and intubation, with anxious noncompliant patients significantly worsening this task. Moreover, airway assessment during the awake state may not correlate with the distortions the airway may undergo in a resting/anesthesized patient. ${ }^{2}$ All these concerns make it clear that the decision on a method of intubation in a patient with a 
neck contracture is a difficult clinical one that should be made by the by the anesthesiologist in consultation with the treating surgeon.

Plastic surgeons have an armamentarium of techniques that can be used to release neck burn contractures. Surgical options vary from the relatively simple lengthening procedures such as z-plasties and band excision used for single band contractures; to contracture/scar excision followed by immediate split- and full-thickness skin grafting and local flaps for larger contractures; to regional, distant, expanded, and free flaps for more extensive injuries. ${ }^{12,13}$

In this retrospective review we have observed that release of mentosternal skin contractures in a significant number of cases does not lead to improvement in airway anatomy and thus does not make the intubation easier or safer in these patients. In our humble opinion, this may be due to continued distortion of inner neck anatomy resulting from the initial insult that has caused the contracture. It may also be caused by gradual changes in the anatomy of the larynx due to forces deforming forces exerted on them by the skin contracture and the flexed neck position. Contraction of skin grafts which are usually used for neck burn contracture release may also play a role in the continued airway deformity of these patients. A major limitation of this article lies in being a retrospective chart review where many of the information might be missing and not standardized. The low number of patients included gives it a low power to draw definite conclusions on which sound decisions can be made. Another limitation is the inability to compare the effectiveness of the different techniques available for scar contracture release and wound coverage and the impact of postoperative care and physical therapy.

Another limitation worth mentioning is the absence of a standardized classification system to describe mentosternal contractures. This makes it difficult to communicate information about area of neck involved and degree of deformity, and therefore may affect treatment recommendations and reproducibility of study results. Tsai et al have described a method of classifying neck contractures by location in the neck, citing central neck above thyroid cartilage, central neck below thyroid cartilage, central neck above and below thyroid cartilage, and lateral neck as areas to be used in the description of neck contractures. ${ }^{1}$ Another classification system is the neck extension deficit grading system where contractures are classified based on the degree to which neck extension is possible. ${ }^{14}$ However, one widely-accepted, easy-toassess system is needed to provide means for easy communication between researchers and a framework for further studies, comparisons and reproducibility of results. The major importance of this article, however, lies in the fact that it is the first time light is shed on this topic paving the way for more research and data collection about this important topic in burn care.

\section{Acknowledgements}

None.

\section{Conflicts of interest}

The authors declare that there is no conflict of interest.

\section{References}

1. Tsai FC, Mardini S, Chen DJ, et al. The classification and treatment algorithm for post-burn cervical contractures reconstructed with free flaps. Burns. 2006;32(5):626-633.

2. Kreulen M, Mackie DP, Kreis RW, et al. Surgical release for intubation purposes in postburn contractures of the neck. Burns. 1996;22(4):310 312

3. Wong TE, Lim LH, Tan WJ, et al. Securing the airway in a child with extensive post-burn contracture of the neck: A novel strategy. Burns. 2010;36(5):e78-81.

4. Adamus W, Fritscherova S, Hrabalek L, et al. Mallampati test as a predictor of laryngoscopic view. Biomed Pap Med Fac Univ Palacky Olomouc Czech Repub. 2010;154(4):339-344.

5. Mallampati R, Gatt SP, Gugino LD, et al. A clinical sign to predict difficult tracheal intubation: A prospective study. Can Anaesth Soc J. 1985;32(4):429-425.

6. Baker PA, Depuydt A, Thompson JM. Thyromental distance measurement-fingers don't rule. Anaesthesia. 2009;64(8):878-882.

7. Rosenstock C, Gillesberg I, Gatke MR, et al. Inter-observer agreement of tests used for prediction of difficult laryngoscopy/tracheal intubation. Acta Anaesthesiol Scand. 2005;49(8):1057-1062.

8. Butler PJ, Dhara SS. Prediction of difficult laryngoscopy: an assessment of thyromental distance and Mallampati predictive tests. Anaesth Intensive Care. 1992;20(2):139-142.

9. Savva D. Prediction of difficult tracheal intubation. Br J Anaesth 1994;73(2):149-153.

10. Frerck CM. Predicting difficult intubation. Anaesthesia. 1991;46(12):1005-1008.

11. Randell T. Prediction of difficult intubation. Acta Anaesthesiol Scand. 1996;40(8 Pt 2):1016-1023.

12. Guven E, Ugurlu AM, Hocaoglu E, et al. Treatment of post-burn upper extremity, neck and facial contractures: report of 77 cases. Ulus Travma Acil Cerrahi Derg. 2010;16(5):401-406.

13. Celikoz M, Sengezer M, Guler MM, et al. Reconstruction of anterior neck contractures with sensate expanded radial forearm free flap. Burns. 1996;22(4):320-323.

14. Yang JY, Tsai FC, Chana JS, et al. Use of free thin anterolateral thigh flaps combined with cervicoplasty for reconstruction of postburn anterior cervical contractures. Plast Reconstr Surg. 2002;110(1):39-46. 